\title{
Acute compartment syndrome following non-contact football injury
}

\author{
P-N Mohanna, F S Haddad
}

\begin{abstract}
Acute compartment syndrome in athletes, although rare, is a limb threatening condition which warrants emergency treatment. The case of a footballer with acute compartment syndrome of the left lower leg, without any preceding direct trauma to the calf, is reported. To our knowledge this is the only description of acute atraumatic compartment syndrome secondary to rupture of one of the heads of gastrocnemius.

(Br F Sports Med 1997;31:254-255)
\end{abstract}

Keywords: football injury; compartment syndrome; gastrocnemius

In acute compartment syndrome, early recognition and decompression are vital to ensure a good functional outcome. ${ }^{12}$ Acute compartment syndrome following a direct blow or a fracture is usually suspected and diagnosed early. ${ }^{34}$ Atraumatic or non-contact acute compartment syndrome is, on the other hand, rare and easily missed $^{5-8}$ We present the case of a semiprofessional footballer who developed acute compartment syndrome of the left lower leg after a rupture of the medial head of gastrocnemius, without any preceding trauma.

\section{Case report}

A 37 year old semiprofessional footballer was waiting to receive a ball with his back to a defender, when he felt as if he had been kicked in the calf. He fell to the ground, and was unable to take any further part in the game. $\mathrm{He}$ noted increasing swelling in his calf that evening, and presented to a physiotherapist and sports medicine doctor the next morning. A diagnosis of a calf strain was made and rest, elevation, ice, and anti-inflammatory medication advised. In spite of this, his pain increased significantly and he presented later that night ( 30 hours after the injury) to his local accident and emergency department with intolerable pain and increased swelling, as well as a feeling of coldness in his foot. It was noted that his Achilles tendon was intact, that his foot pulses were present and that he had active movement in his foot. $\mathrm{He}$ was given stronger analgesia and discharged.

The next day, the patient's pain abated a little, but he developed sensory symptoms, particularly over the dorsum of his foot and therefore presented to our department. Clinical examination showed a young fit man with a swollen painful left calf $10 \mathrm{~cm}$ larger than the contralateral side. The whole lower leg had a shiny hue and his foot felt colder than the other side. His superficial veins were dilated. Peripheral pulses were palpable, but capillary refill was reduced.

He was exquisitely tender on palpation of his gastrocnemius, particularly medially. Palpation and Simmond's test showed a painful but intact Achilles tendon. Passive movements of his ankle caused pain in his calf. Flexion and extension strength of the toes was slightly diminished as compared with the contralateral side. Sensation was subjectively and objectively decreased, particularly over the dorsum of his foot in the area of distribution of the peroneal nerve. Vibration sense was present, but joint position sense was reduced.

The patient was immediately taken to the operating theatre for compartment pressure measurements. These were performed by the insertion of a cannula at several levels in each compartment. The cannula was connected to a calibrated arterial monitor which measured the pressure in that compartment. The readings indicated average pressures of over $100 \mathrm{~mm} \mathrm{Hg}$ in all compartments on the left side. This compared with a diastolic pressure of $60 \mathrm{~mm} \mathrm{Hg}$ and with pressures on the contralateral side that averaged $23 \mathrm{~mm} \mathrm{Hg}$.

An emergency two incision four compartment fasciotomy was therefore carried out. A complete rupture of the medial belly of the gastrocnemius with a massive haematoma in the gastrocnemius-soleus complex was found. The anterior, lateral, and superficial posterior compartments were all greatly distended with dusky but viable muscle. The deep posterior compartment was also distended but with no evidence of muscle injury. After evaluation of the haematoma in the gastrocnemius-soleus complex, we were not able to approximate the torn ends of the muscle which was left gaping. After the fasciotomy the patient's wounds were dressed and his leg elevated. His pain settled and subsequent reinspections in theatre showed all his muscle to be viable with no evidence of necrosis. The peroneal nerve and its superficial branch were both seen to be intact. As it was only possible to close the lateral fasciotomy wound, the medial side was covered with a split skin superficial graft. This took well and he was discharged 15 days after admission.

On review in outpatients, the patient's wounds were healing well, although he still had significant discomfort over the medial belly of the gastrocnemius. His residual neurological symptoms consisted of sensory loss, which was greatest in the deep peroneal distribution, but which was also apparent in the distribution of 
the superficial peroneal nerve. Sensation and strength were all steadily improving.

\section{Discussion}

A high index of suspicion and careful clinical evaluation will detect most impending or established cases of compartment syndrome. Compartment pressure measurements are a useful adjunct to evaluation. If they are higher than $\mathbf{4 0 ~} \mathrm{mm} \mathrm{Hg}$, then urgent decompression is called for. ${ }^{1}$ Recent studies advocate the determination of the difference between the mean arterial and compartmental pressures rather than absolute tissue pressure measurements. ${ }^{910}$ Our case easily satisfied both sets of criteria.

Once the diagnosis of compartment syndrome is confirmed or suspected, fasciotomy should be performed without delay. This entails incision of the underlying skin and investing fascia of the compartment, relieving pressure and enhancing tissue perfusion. Delayed primary closure is recommended, but skin edge retraction often necessitates a split thickness skin graft. ${ }^{11}$

In our patient rupture of the medial head of gastrocnemius caused bleeding into the superficial posterior compartment and an increase in intracompartmental pressure. This eventually also led to compromise of the anterior and lateral compartments. Allen and Barnes ${ }^{12} \mathrm{de}-$ scribed an acute superficial posterior compartment syndrome following a non-contact squash injury. Urgent fasciotomy led to an uneventful recovery. The delay in our case probably accounts for involvement of the other compartments because of continuing haemorrhage. This prolonged period of elevated intracompartmental pressure would also explain the residual neurological symptoms and signs.

Moyer et $a l^{13}$ retrospectively reviewed three patients who developed atraumatic acute compartment syndrome of the lower extremity, with injuries sustained in a similar manner to an ankle sprain. The compartment syndromes appeared to arise in a similar manner as a result of a muscle strain or tear with haemorrhage into the compartment. Williams et $a l^{14}$ presented a case where rupture of peroneus longus caused haemorrhage into the lateral compartment which resulted in a delayed diagnosis of compartment syndrome.

The case presented illustrates the potential dangers of an apparently benign non-contact injury. It emphasises the importance of a full examination and a high index of suspicion for compartment syndrome whenever any painful soft tissue injury is being assessed.

1 Mubarak SJ, Hargens AR, Owen CA, Garetto LP, Akeson WH. The wick catheter technique for the measurement of intramuscular pressure. $f$ Bone foint Surg Am intramuscular prest

2 Gulli B, Templeman D. Compartment syndrome of the lower extremity. Orthop Clin North Am 1994;25:677-84.

3 Geogiadis GM. Tibial shaft fractures complicated by compartment syndrome: treatment with immediate fasciotomy and locked unreamed nailing. $F$ Trauma 1995;38: 448-52.

4 McQueen MM, Christie J, Court-Brown CM. Acute compartment syndrome in tibial diaphyseal fractures. Bone foint Surg Br 1996;78:95-8.

5 Blandy JP, Fuller R. Ischaemic myositis of the leg muscles from exercise. F Bone foint Surg Br 1957;39:679-93.

6 Kirby NG. Exercise ischaemia in the fascial compartment of soleus. $\mathcal{F}$ Bone foint Surg Br 1970;52:738-40.

7 McKee MD, Jupiter JB. Acute exercise-induced bilatera McKee MD, Jupiter JB. Acute exercise-induced bilateral young man. Am f Orthop 1995;24:862-4.

8 McHale KM, Prahinski JR. Acute exertional compartmen syndrome occurring after performance of the army physica fitness test. Orthopaedic Review 1994;23:749-53.

9 McQueen MM, Court-Brown CM. Compartment monitoring in tibial fractures. $\mathcal{F}$ Bone foint Surg Br 1996;78:99-104

10 Mabee JR, Bostwick TL. Pathophysiology and mechanism of compartment syndrome. Orthopaedic Review 1993;22 $175-81$

11 Berman SS, Schilling JD, McIntyre KE, Hunter GC, Bernhaud VM. Shoelace technique for delayed primary closure of fasciotomies. Am $₹$ Surg 1994;167:435-6.

12 Allen MJ, Barnes MR Unusual cause of acute superficia Allen MJ, Barnes MR. Unusual cause of acute superficial Moyer RA, Boden BP, Marchetto PA, Kleinbart F, Kelly JD. Moyer RA, Boden BP, Marchetto PA, Kleinbart F, Kelly JD.
Acute compartment syndrome of the lower extremity scute compartment syndrome of the lower extremity 7 .

14 Williams P, Shenolikar A, Roberts RC and Davies RM Acute non-traumatic compartment syndrome related to soft tissue injury. Injury 1996;27:507-8.

\section{Commentary}

This is a fascinating case report. As has been pointed out by the authors these conditions are rare but can have serious consequences if missed. Without doubt the initial insult was the ruptured gastrocnemius, confirmed by both the symptoms and operative findings. However, the most interesting aspect is how did the anterior compartment become affected?

Almost by definition the four compartments of the lower leg act as discrete pressure units; a raised pressure in one is rarely transmitted to the others, and indeed extensive experience of measuring compartment pressures has shown this to be the case.

In this instance, however, the raised pressure in the superficial posterior compartment was transmitted, not just into the adjacent compartments, but right across the leg to cause a definite anterior compartment syndrome, with grossly increased pressure and long term neurological deficits in the distribution of the deep peroneal nerve.

I would be very interested in any ideas the authors may have as to how this might have occurred. Could it be the length of time involved? If so, this case strongly emphasises the importance of early diagnosis and treatment. 